\title{
Developing EU environmental standards for the food, drink and milk industries: key environmental issues and data collection
}

\author{
Germán Giner Santonja* (i) and Panagiotis Karlis
}

\begin{abstract}
Background: The European Commission organised the review of the best available techniques reference document for the food, drink and milk industries according to the provisions of the Industrial Emissions Directive (Directive 2010/75/EU). Under this policy, an exchange of information between Member States, industrial organisations, nongovernmental organisations promoting the protection of the environment and the European Commission took place.

Results: A crucial part of developing these EU environmental standards was the systematic determination of the key environmental issues of the food, drink and milk sector. Key environmental issues were defined for emissions to air and water, and for energy and water consumption. The key environmental issues were systematically determined using four criteria proposed by the European Commission. Moreover, a data collection procedure was designed and real-plant emissions and consumption data were obtained for the first time from a representative variety of food, drink and milk installations across the European Union.

Conclusions: The development of the EU environmental standards for the food, drink and milk sector are based on a systematic determination of the key environmental issues and on a representative data collection for this sector. This paper also highlights the main normative, organisational and procedural factors addressed during the environmental policy integration carried out to develop these standards.
\end{abstract}

Keywords: Best available techniques, Food, drink and milk industries, Industrial Emissions Directive, Key environmental issues, Environmental policy integration

\section{Background}

The European food, drink and milk (FDM) sector produces both finished products destined for consumption and intermediate products destined for further processing. Europe's food and drink industry was the largest manufacturing industry in the EU-28 with an annual turnover of EUR 1039 billion and 4.42 million jobs in 2016. This represented $14.6 \%$ of the total manufacturing sector turnover and $14.5 \%$ of the total manufacturing sector employment in the EU-28. This industrial sector is highly fragmented with almost 290000 companies, the

*Correspondence: german.giner-santonja@ec.europa.eu European Commission, Joint Research Centre (JRC), Sevilla, Spain majority of which are small and medium-sized enterprises [12].

Furthermore, the EU-28 FDM sector is characterised by its diversity compared to many other industrial sectors. This diversity can be seen in many aspects, e.g. in the configuration and size of companies, the wide range of raw materials and products, and the numerous processes and the combinations of these [12].

The original Best Available Techniques Reference Document (BREF) on Food, Drink and Milk Industries was formally adopted by the European Commission in 2006 [4] under the IPPC Directive [2]. This document described the key environmental issues of the FDM sector, although they were not determined systematically. 
Moreover, a plant-specific data collection from real FDM industries was not carried out at that time.

Data from the European Pollutant Release and Transfer Register (E-PRTR) show that FDM industries represent a small share of the total industrial emissions for most of the pollutants reported [3]. However, the number of installations and substances identified by this approach needs to be treated with caution because it is strongly influenced by the E-PRTR reporting thresholds. For example, there may be substances that are emitted by a large number of FDM installations, but at levels just below the E-PRTR reporting threshold so those installations will not appear in the E-PRTR.

Another report [15] attempted to assess the significance of pollution caused by the FDM industries, in particular by allowing the comparison and/or aggregation of different pollutants. The report described different methods such as weighting the pollutants according to their human health toxicity and ecotoxicity. This report also indicated a low significance of the pollution caused by the FDM industries, compared to other industrial sectors. This report needs to be analysed carefully, considering the uncertainties inherent in the USEtox model used to characterise the toxicity and ecotoxicity of various substances.

The adoption of the Industrial Emissions Directive (2010/75/EU) [10] reinforced the legal nature of the best available techniques (BAT). Due to the legal nature of this type of environmental standard, the development of BAT for the FDM industries needed to be based on sound scientific evidence.

Standards play a key role in defining desirable levels of environmental protection and as an effective tool to regulate environmental issues including in countries outside the EU [14]. Moreover, the participation of nongovernmental stakeholders, including industry and environmental organisations, in determining the benchmarks upon which policies are enacted is deemed extremely important. In this sense, the reference documents on best available techniques (BREFs) are considered a vital basis for the development of environmental standards worldwide. Furthermore, the necessity for environmental policy integration has become a key endeavour, as governments prepare to implement the 2030 Agenda and the 17 Sustainable Development Goals adopted by the UN General Assembly in 2015 [18]. In this regard, EU institutions have to a large extent formalised and operationalised environmental policy integration commitments [21].

Three types of factors can be addressed in environmental policy integration: normative factors, organisational factors and procedural factors [17, 22]. Normative factors refer to the legal framework of the policymaking [23], organisational factors include the interaction of stakeholders [20], and procedural factors refer to the procedure carried out for the environmental policy integration [19]. The main normative factors of the environmental standards addressed by this paper, i.e. the most relevant articles of the Industrial Emissions Directive, are described in "Legal framework: the industrial emissions directive" section, the organisational factors (e.g. the type of experts involved in the decision making process, meetings of experts and procedural factors (steps for the determination of key environmental issues, the data collection process and the main steps for the adoption of the environmental standards are summarised in "The procedure for KEI and data collection" section. This paper describes a case of policy implementation, which is a critical step for environmental policy integration [21].

A study was carried out with the following key aims: (1) determine the key environmental issues for the FDM industries; (2) analyse the environmental performance of FDM installations and techniques in terms of emissions, consumption and nature of raw materials, water and energy consumption, through a data collection from FDM industries.

As explained in "Methodology" section of this paper, the key environmental issues and the environmental performance of the FDM industries are essential to develop the environmental standards known as best available techniques. "Methodology" section also describes the main factors of the environmental policy integration used to develop these EU environmental standards. "Results" section describes the outcome of the determination of the key environmental issues and of the data collection performed to analyse the environmental performance of the FDM industries in the EU.

\section{Methodology}

\section{Legal framework: the Industrial Emissions Directive}

The Industrial Emissions Directive (2010/75/EU) [10] is the primary EU legal instrument to regulate industrial emissions and aims to achieve significant benefits for the environment and human health, in particular through the application of Best Available Techniques (BAT) while ensuring a level playing field for industry.

The scope of the Industrial Emissions Directive (IED) covers a large spread of industrial sectors and activities (e.g. combustion plants, production of cement, lime and magnesium oxide, intensive rearing of poultry and pigs, waste management), usually over a certain capacity threshold, specified for individual sectors and activities. All these industrial sectors and activities as well as their respective capacity threshold (if relevant) are defined in Annex I to the IED.

The IED regulates pollutant emissions to air, water and soil, and aims to prevent the generation of waste 
and promote the efficient use of resources from about 50000 industrial installations across the European Union (EU). These industrial installations generate almost a quarter of the total EU emissions to air and water. It is estimated that they account for around $23 \%$ by mass of emissions to air. For emissions to water, the situation is less clear, but it is estimated that they generate $20 \%$ to $40 \%$ of emissions of heavy metals and $30 \%$ to $60 \%$ of pollutants other than nutrients and organic carbon [8].

The installations covered by the IED must be operated in accordance with a permit granted by the relevant competent authority in the Member States. The technical basis for national competent authorities in EU countries to set permit conditions for industrial installations is the BAT conclusions. BAT conclusions cover a variety of environmental issues such as emissions to air and to water, waste generation, energy efficiency and water consumption [5].

Permit conditions must be based on the use of BAT, with the BAT conclusions adopted by the European Commission serving as the reference for setting these conditions. BAT are defined as established techniques which are the most effective at achieving a high level of protection of the environment as a whole and which are developed on a scale that allows implementation in the relevant sector under economically and technically viable conditions taking into account the costs and advantages [10].

The techniques listed and described in the BAT conclusions are neither prescriptive nor exhaustive. Other techniques that ensure at least an equivalent level of environmental protection may be used. The selection of (a) technique(s) to prevent or reduce a specific pollutant at installation level is a decision that depends on various factors, such as the technical configuration of the installation, the raw materials used, economics, sector legislation or safety issues [5].

An individual BAT conclusion with BAT-associated emission levels (BAT-AELs) will contain a numerical range of emission levels. The units, the reference conditions (e.g. flue-gas oxygen level, temperature, pressure) and the averaging period (e.g. hourly/daily/weekly/ monthly/yearly average) for a given BAT-AEL must be unambiguously defined. If considered necessary, and if the data available allow for doing so, BAT-AELs may be expressed as short-term and long-term averages [13]. The Member States' competent authorities shall set emission limit values that ensure that, under normal operating conditions, emissions do not exceed the emission levels associated with the best available techniques [10].

Environmental performance levels (BAT-AEPLs) other than emission levels can be associated with certain BAT. Examples include the consumption of materials, water or energy, the generation of waste, the abatement efficiency on pollutants and the duration of visible emissions.

According to the IED, the Commission should organise an exchange of information with Member States, the industries concerned and non-governmental organisations promoting environmental protection in order to draw up, review and, where necessary, update BAT reference documents (hereafter BREFs). That exchange of information shall, in particular, address the following [10]:

- The performance of installations and techniques in terms of emissions, consumption and nature of raw materials, water and energy consumption, and generation of waste;

- The techniques used, economic and technical viability and developments therein;

- Best available techniques.

A best available techniques (BAT) reference document (BREF), resulting from this exchange of information, is a document drawn up for defined activities describing, in particular, applied techniques, current emission and consumption levels, techniques considered for the determination of BAT as well as BAT conclusions and emerging techniques [5].

In more detail, 'BAT conclusions' are defined as the parts of a BREF laying down the conclusions on BAT, their description, information to assess their applicability, the emission levels associated with the BAT, associated monitoring, associated consumption levels and, where appropriate, relevant site remediation measures. The BAT conclusions are adopted through the procedure referred to in Article 75(2) of the IED. They shall be the reference for setting permit conditions for the installations covered by the IED [10].

Best available techniques (BAT) are defined as the most effective and advanced stage in the development of activities and their methods of operation, to reduce emissions and the impact on the environment as a whole [10]:

a. 'Techniques' includes both the technology used and the way in which the installation is designed, built, maintained, operated and decommissioned;

b. 'Available techniques' means those developed on a scale which allows implementation in the relevant industrial sector, under economically and technically viable conditions, taking into consideration the costs and advantages, whether or not the techniques are used or produced inside the Member State in question, as long as they are reasonably accessible to the operator; 
c. 'Best' means most effective in achieving a high general level of protection of the environment as a whole.

The BAT conclusions document for a specific industrial sector contains several individual conclusions, each of them addressing an environmental objective related to the prevention or reduction of one or more pollutants. The IED permits should make reference to one or a combination of the techniques listed in the corresponding BAT conclusion(s). The IED sets the objective to review each BREF every 8 years in order to reflect technical progress.

The reviews of BREFs are coordinated by the European Integrated Pollution Prevention and Control Bureau (EIPPCB), part of the Joint Research Centre that belongs to the European Commission. Evidence-based decisions on BAT and BAT-AEPLs are taken with the consensus of the Technical Working Group members (see "Legal framework: the industrial emissions directive" section). The information collected during a BREF review is shared among the TWG members through an online platform called BATIS (BAT Information System). Whilst an evaluation based on quantitative data is preferable, qualitative information, such as stakeholder opinions and criteria, is an important complement to quantitative data.

Food, drink and milk industries are covered by points 6.4 (b) and 6.4 (c) of Annex I to the IED. Specifically, these points state the following [10]:
"6.4 (b) Treatment and processing, other than exclusively packaging, of the following raw materials, whether previously processed or unprocessed, intended for the production of food or feed from:

i. Only animal raw materials (other than exclusively milk) with a finished product production capacity greater than 75 tonnes per day;

ii. Only vegetable raw materials with a finished product production capacity greater than 300 tonnes per day or 600 tonnes per day where the installation operates for a period of no more than 90 consecutive days in any year;

iii. Animal and vegetable raw materials, both in combined and separate products, with a finished product production capacity in tonnes per day greater than:

75 if $A$ is equal to 10 or more; or,

$[300-(22.5 \times A)]$ in any other case,

where ' $A$ ' is the portion of animal material (in percent of weight) of the finished product production capacity.

Packaging shall not be included in the final weight of the product.

This subsection shall not apply where the raw material is milk only.

6.4 (c) Treatment and processing of milk only, the quantity of milk received being greater than 200 tonnes per day (average value on an annual basis)." (Fig. 1).

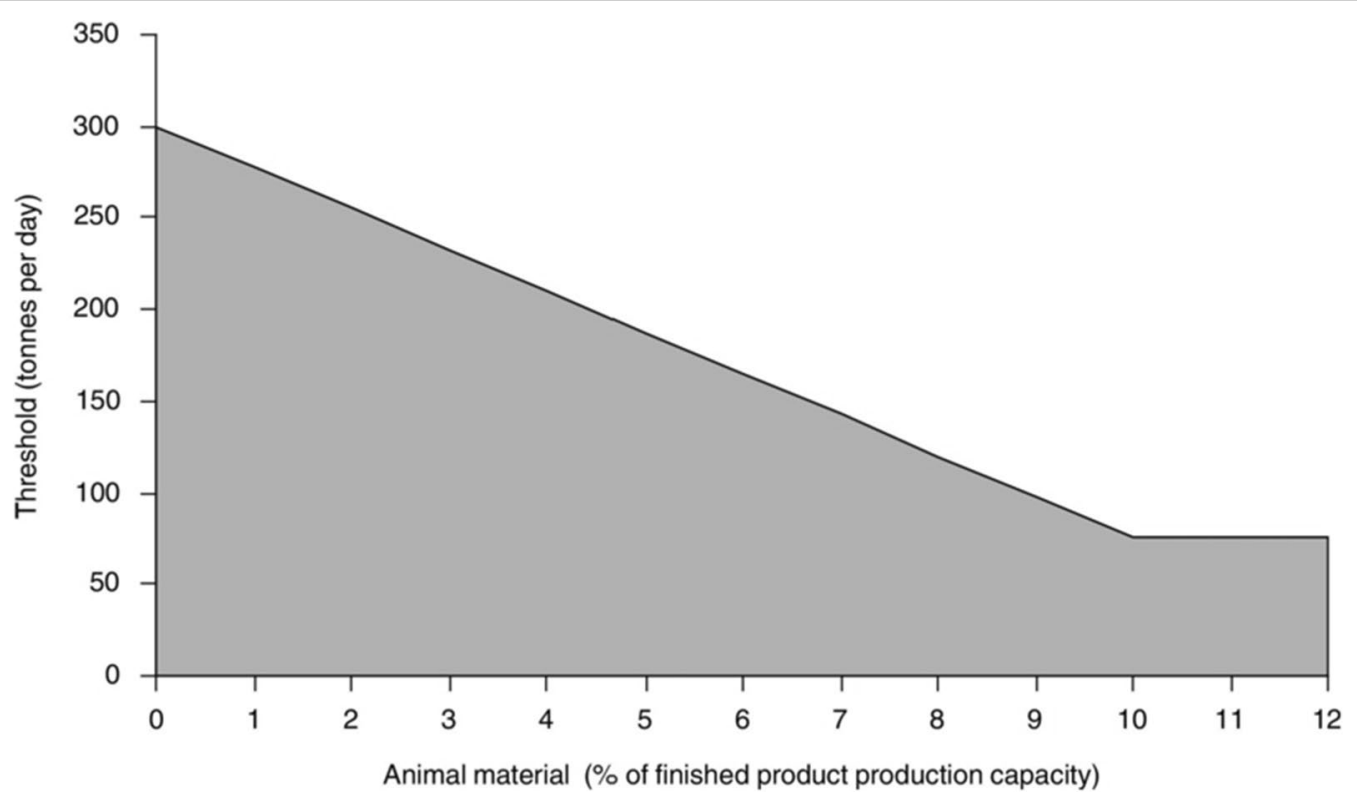

Fig. 1 IED threshold for activity 6.4 (b) iii [10] 


\section{The procedure for KEI and data collection}

A technical working group (TWG) was created to discuss the key environmental issues and the process for data collection from the FDM industries. The TWG is the main source of information for the drawing up and reviewing of a BREF. It comprised the relevant technical experts from Member States, industrial organisations and non-governmental organisations for the protection of the environment [5].

The TWG for the review of the FDM BREF was reactivated in early 2014 and it consisted of around 180 technical and regulatory experts. The TWG for the review of the FDM BREF held its Kick-off Meeting (KoM) in Seville, Spain, on 27 to 30 October 2014.

Around 80 experts representing national competent authorities, industrial organisations and non-governmental organisations attended the KoM. Experts covering a large spread of the food sector (e.g. dairies, breweries, sugar manufacturing, starch production, animal feed, oilseed processing and refining, meat production) were present at the KoM. This representativeness was extremely important, taking into account the diversity of the sector and the numerous different applied processes and techniques.

The meeting focused on the key environmental issues (KEIs) of the FDM sector, on the most effective arrangements for exchanging and gathering information on best available techniques (addressing the basic features required by Article 13 of the IED), on the definition of the scope of the FDM BREF and on issues related to the data and information collection.

KEIs are a tool to focus the TWG resources on a manageable number of issues. It is important for KEIs to be identified at the beginning of a BREF review process with the intention of deriving BAT-AELs or other BAT-AEPLs for these KEIs.

The following criteria have been proposed by the European Commission for the identification of KEIs [6]:

i. The environmental relevance of the (air, water, or soil) pollution caused by the activity or process concerned, i.e. whether it may cause an environmental problem.

ii. The significance of the activity in terms of number of installations, their geographical spread and their contribution to the total (industrial) emissions in the EU.

iii. The potential of the BREF review for identifying new or additional techniques that would further significantly reduce pollution.

iv. The potential of the BREF review for defining BATAELs that would significantly improve the level of protection of the environment as a whole in comparison with the current emission levels.

In order to assist the discussions during the KoM, a background paper detailing the main items to be discussed was prepared by the European Integrated Pollution Prevention and Control Bureau (EIPPCB) and sent to the TWG members in advance of the meeting. The items had been derived from about 1000 initial positions sent by the TWG in advance of the KoM. Initial positions are preliminary suggestions and comments provided by the members of the TWG.

The data collection took place by using a tailor-made questionnaire (see "Data collection" section). The questionnaire is an important tool for every BREF review process, since it should enable the efficient and comprehensive collection of representative data and contextual information for the derivation of technically sound BAT conclusions.

Around 2800 European FDM installations are covered by the IED $[7,12]$. The TWG applied several criteria for selecting plants for the plant-specific data collection via questionnaires, in order to ensure a balanced representation of the FDM sector:

- The environmental performance.

- The use of BAT and innovative techniques.

- The production capacity-both small and large.

- The age of the plant-both newer and older.

- The processes-single and multi-product processes.

- The FDM subsector.

- Geographical distribution.

- Products/processes that required a dedicated approach due to their environmental relevance.

- Availability of data.

A first draft questionnaire template (in Excel form) was prepared by the EIPPCB and distributed to the TWG for their comments. Based on these comments, the EIPPCB updated the first draft questionnaire and a TWG meeting took place in Brussels to finalise it. The final draft questionnaire was tested by a limited number of FDM installations. Once the questionnaire was finished, it was distributed by EU Member States' representatives to the selected plants. The EU Member States' representatives were also responsible for collecting the filled-in questionnaires, checking the quality of the data and submitting the quality-checked questionnaires to the EIPPCB.

The questionnaire was designed in such a way that avoided requesting confidential data as much as possible. The only information considered confidential was the amount of energy consumed and raw materials used as well as the amount of products. 
In parallel to the FDM data collection, the TWG collected information on the applied processes and techniques in the different FDM subsectors, on the techniques to be considered for the determination of BAT and on the emerging techniques. These techniques covered both pollution prevention and control measures, and the information included the following elements: technical description, achieved environmental benefits, environmental performance and operational data, crossmedia effects, technical considerations relevant to applicability, economics, driving force for implementation, example plants and related reference literature. Around 100 contributions/sources of qualitative information were used to update the FDM BREF.

Based on the new information/data, a draft of the revised FDM BREF was produced and made available to the whole TWG for their comments. A major update was the inclusion of real-plant consumption and emission data for the key environmental issues identified (see "Results" section).

The TWG members submitted 1963 comments in relation to the draft FDM BREF. The majority of them (around 60\%) were on the BAT conclusions chapter of the FDM BREF. The EIPPCB assessed all the comments and made proposals, which were then incorporated in the final draft of the FDM BREF.

An intense 5-day final meeting took place in Seville (Spain) between 14 and 18 May 2018, involving around 80 TWG members. The purpose of the final meeting is for the TWG to conclude the technical discussions and decide on BAT for the sector. The basis of the meeting was a background paper produced by the EIPPCB taking into account the TWG comments on the BAT conclusions section of the draft FDM BREF.

A consensus was achieved during the final meeting on the BAT for the FDM sector, consisting of 37 individual BAT conclusions. Of these, 4 covered general aspects including environmental management and monitoring practices, 8 related to energy efficiency, 3 to resource efficiency, 2 to harmful substances, 2 to water consumption and waste water discharge, 3 to waste, 10 to emissions to air, 2 to emissions to water, 1 to odour and 2 to noise.

Based on the outcome of the final meeting and the TWG comments on the draft FDM BREF, a pre-final draft was produced for the TWG to verify that the decisions taken at the final meeting were taken on board in the BREF. The TWG comments on the pre-final draft were used to produce the final draft of the FDM BREF.

Further steps outside the remit of the TWG were followed, in relation to the opinion of the formal IED Forum (November 2018) on the final draft of the revised FDM BREF, and the positive vote by EU Member States (decided by a qualified majority in June 2019) on the BAT conclusions, required to proceed with the legal adoption of the BAT conclusions by the Commission and the publication in the Official Journal of the European Union [9]. The revised FDM BREF is publicly available on the EIPPCB website [12].

\section{Results \\ Key environmental issues \\ Emissions to water}

In general terms, waste water originating from the FDM industry is, in most cases, biodegradable. Taking this into account, along with the information in the FDM BREF adopted in 2006 and in the initial TWG positions, the EIPPCB considered that there was a basis for a horizontal proposal across the FDM sector in relation to the KEIs for emissions to water. Therefore, the EIPPCB initially proposed chemical oxygen demand (COD), total suspended solids (TSS), total nitrogen (TN) and total phosphorus (TP) as KEIs.

The EIPPCB also proposed total organic carbon (TOC) as a KEI as an alternative to COD. The basis of this proposal is that the analytical method for COD measurement includes the use of the toxic dichromate compound.

Furthermore, it was proposed to collect data for the parameters biochemical oxygen demand (BOD) and ammonium nitrogen, but only as contextual information to assess the performance of the waste water treatment plant. Biodegradable compounds covered by BOD are a subset of all organic matter present in the waste water. BOD is therefore included in the parameter $\mathrm{COD} / \mathrm{TOC}$. Moreover, the measurement uncertainty for BOD is higher than for COD/TOC and the monitoring result is only available several days after sampling [1].

The discussion at the KoM showed that the EIPPCB proposals were largely acceptable. There was general concern about the availability of data in relation to TOC. The merit of promoting the measurement of TOC was explained by the EIPPCB. It was also clarified that the intention was to collect all the available TOC data and that the TWG assessment would show the suitability of establishing a related BAT-AEL or not.

It was also agreed during the KoM to collect data for $\mathrm{Cl}^{-}$emissions to water for dairies and fish and shellfish processing, since brine is generated from various processes within these sectors (e.g. production of cheese, demineralised powder, fish processing and preservation).

Table 1 presents a general overview of the key environmental issues for emissions to water agreed on at the KoM for the review of the FDM BREF across the 13 FDM sectors for which data were collected. 
Table 1 Key environmental issues for emissions to water from the FDM sector (adapted from [12])

\begin{tabular}{llc}
\hline FDM subsector & Common parameters & Additional parameters \\
\hline Dairies & TOC, COD, TSS, TN, TP & ${\mathrm{Chloride}\left(\mathrm{Cl}^{-}\right)}^{-}$ \\
Sugar manufacturing & & - \\
Fruit and vegetables & - \\
Meat processing & - \\
Animal feed & - \\
Oilseed processing and vegetable oil refining & - \\
Starch production & & - \\
Brewing & & $\mathrm{Chloride}\left(\mathrm{Cl}-^{-}\right)$ \\
Fish and shellfish processing & - \\
Olive oil processing and refining & - \\
Soft drinks and juice made from concentrate & & - \\
Ethanol production & & - \\
Grain milling & - & - \\
\hline
\end{tabular}

\section{Emissions to air}

A different pattern was followed to decide on the KEIs for emissions to air. The diversity of the applied processes in the FDM sector made it necessary to discuss the KEIs using a sector-by-sector approach, identifying the different air pollutants and the relevant emission sources. Overall, it was concluded that dust was the predominant $\mathrm{KEI}$ in relation to emissions to air.

The emission source is important contextual information in relation to emissions to air. For some FDM subsectors, the TWG decided at the KoM on the KEIs without any indication of the emission source. At a later stage of the FDM BREF review process, the TWG identified the major emission sources for emissions to air.

Table 2 presents an overview of the key environmental issues for channelled emissions to air with an indication of the emission sources.

On-site combustion plants to produce electricity or heat are excluded from the scope of the FDM BREF, as they are covered by the scope of the Large Combustion Plants BREF [16] or by the scope of Directive EU/2015/2193 [11].

Table 2 Key environmental issues for channelled emissions to air from the FDM sector (adapted from [12])

\begin{tabular}{lll}
\hline Substance/parameter & FDM subsector & Emission source \\
\hline Dust & Animal feed & Drying of green fodder \\
& Brewing & Compound feed manufacturing \\
& Dairies & Handling and processing of malt and adjuncts \\
& Grain milling & Drying processes \\
& Oilseed processing and vegetable oil refining & Grain cleaning and milling \\
& Starch production & Handling and preparation of seeds, drying and \\
& Sugar manufacturing & cooling of meal \\
& Fish and shellfish processing & Drying of starch, protein and fibre \\
Total volatile organic carbon & Meat processing & Drying of beet pulp \\
& Oilseed processing and vegetable oil refining & Smoke chambers \\
& Sugar manufacturing & Smoke chambers \\
$\mathrm{NO}_{\mathrm{X}}$ & Meat processing & - \\
& Sugar manufacturing & High-temperature drying of beet pulp \\
$\mathrm{SO}_{\mathrm{X}}$ & Meat processing & Smoke chambers \\
& Sugar manufacturing & High-temperature drying of beet pulp
\end{tabular}




\section{Energy consumption}

FDM manufacturing generally requires significant amounts of energy. Electrical and thermal energy are commonly used in every process step. Electricity is normally needed for process control of the installation, for heating, for refrigeration and as the driving power for machinery. Thermal energy is normally needed for heating processing lines.

Energy consumption was largely recognised as a KEI for the FDM sector by the TWG members. The TWG decided at the KoM to collect data and contextual information on the consumption of energy for relevant FDM subsectors [12].

\section{Water consumption}

A large part of the FDM sector cannot operate without a substantial amount of usually good-quality water. Water is generally used in the FDM sector for:

- Food processing, where the water either comes into contact with or is added to the product.

- Cleaning of equipment and the installation.

- Washing of raw and packaging materials.

- Auxiliary processes, e.g. boilers, cooling circuits, refrigeration.

Hygiene and food safety standards have to be maintained and this issue affects the proportion of water that can be recycled and reused.

As for energy consumption, water consumption was largely recognised as a KEI for the FDM sector by the TWG members. The TWG agreed at the KoM to collect data and contextual information on the consumption of water for relevant FDM subsectors [12].

\section{Data collection}

The diversity of the FDM sector required that the data collection be focused on a defined group of FDM subsectors. Factors such as the information included in the FDM BREF adopted in 2006 and the number of FDM installations across Europe were taken into account. The TWG decided that the FDM subsectors for which emission data would be collected via questionnaires were the following:

- Animal feed.

- Brewing.

- Dairy sector.

- Ethanol production, taking place in a FDM installation or as a directly associated activity.

- Fish and shellfish processing.

- Fruit and vegetables.
- Grain milling.

- Meat processing.

- Oilseed processing and vegetable oil refining.

- Olive oil processing and refining.

- Soft drinks and nectar/juice.

- Starch production.

- Sugar manufacturing.

The data and information requested by the final questionnaire regarding emissions to water consisted mainly of the following:

- Type of waste water discharge: direct, indirect or landspreading.

- Volume of waste water discharged (in $\mathrm{m}^{3} /$ year).

- Volume of waste water reused/recycled (in $\mathrm{m}^{3} /$ year).

- Share of waste water treated in the waste water treatment plant (WWTP) from sources other than from the FDM activity (e.g. municipal waste water, industrial waste water other than that originating from the FDM activity).

- Waste water treatment techniques.

- Emission levels for each KEI, expressed in concentrations and specific loads for the influent and effluent of the WWTP. Statistical values were requested for each year: minimum, average, 95th percentile, maximum.

- For each KEI: number of measurements taken during 1 year, measurement method, emission limit values prescribed by the competent authority in the permit.

- In the case of a FDM installation with a seasonal activity: duration of the campaign period (in months).

The data and information requested by the final questionnaire regarding emissions to air for the major emission sources consisted mainly of:

- Type of emission source and processes connected to it;

- Waste gas flow $\left(\mathrm{Nm}^{3} / \mathrm{h}\right)$ and oxygen level (\% by volume).

- Abatement techniques implemented for the emission source.

- For each KEI: number of measurements taken during 1 year, measurement method, average abatement efficiency, emission limit values prescribed by the competent authority in the permit.

- In the case of a dryer: type of dryer, type of dried product, characterisation of the dust fraction.

- In the case of a FDM installation with seasonal activity: duration of the campaign period (months). 
The data and information requested by the final questionnaire regarding energy consumption consisted mainly of:

- Total amount of energy consumed by the FDM installation (MWh/year).

- Energy consumption (MWh/year) by use, e.g. in the FDM process, for cooling, for cleaning.

- Techniques implemented for the reduction of energy consumption.

The data and information requested by the final questionnaire regarding water consumption consisted mainly of:

- Total amount of water consumed by the FDM installation (in $\mathrm{m}^{3} /$ year).

- Source(s) of the inlet raw water (e.g. water supply network, seawater, underground water).

- Water consumption (in $\mathrm{m}^{3} /$ year) by use, e.g. in the FDM process, for cleaning, for cooling;

- Total amount of water recycled/reused (in $\mathrm{m}^{3} /$ year).

- Techniques implemented for the reduction of water consumption and water reuse or recycling.

Additionally, the following data were requested for all FDM installations:
- Total amount and share of raw materials and/or products.

- Type and frequency of cleaning procedures.

- Chemicals and other substances used for cleaning.

- Characteristics of the main residues, wastes and byproducts generated by the FDM installation.

Data from 353 European FDM installations, gathered for the years 2012 to 2014, were collected using the final questionnaire. These questionnaires were validated and submitted by 16 EU Member States, ensuring a satisfactory representation at EU level. This was an important step in comparison to the FDM BREF adopted in 2006.

The distribution of the submitted questionnaires in relation to the FDM subsectors is depicted in Fig. 2.

Overall, the agreed FDM subsectors were well represented, except for olive oil processing and refining along with fish and shellfish processing and ethanol production. The majority of the submitted questionnaires referred to dairies, followed by the brewing subsector.

Validated data were subsequently assessed and discussed within the TWG (e.g. through the comments provided on the first draft of the revised FDM BREF and during two dedicated data assessment workshops). This assessment was essential for drawing up BAT conclusions and setting BAT-AELs.

Due to the large amount of data collected, this paper only presents a few examples, e.g. Tables 3, 4, 5 and 6

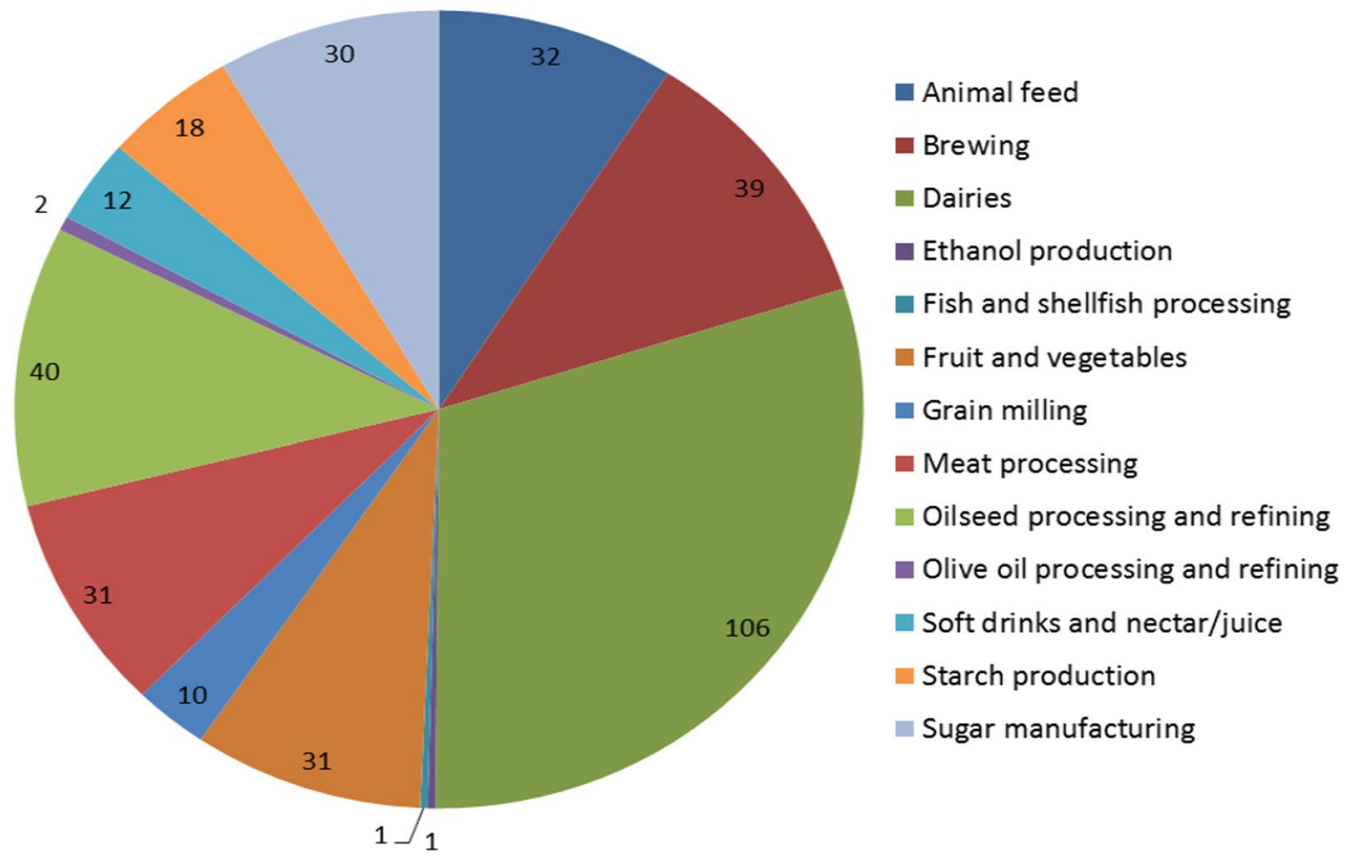

Fig. 2 Distribution of submitted questionnaires in relation to the FDM subsectors (adapted from [12]) 
Table 3 Ranges of yearly average concentrations of TSS in the effluent of the WWTP [12]

\begin{tabular}{|c|c|c|c|}
\hline \multirow[t]{2}{*}{ FDM subsector } & \multicolumn{3}{|c|}{ Yearly average TSS concentration (mg/l) } \\
\hline & Direct discharge & Indirect discharge & Landspreading \\
\hline Animal feed & $4.6-97$ & $91-303$ & $\mathrm{NI}$ \\
\hline Brewing & $2.5-21$ & $1.58-1095$ & $\mathrm{NI}$ \\
\hline Dairies & $0.6-41.4$ & 18-1095 & $\mathrm{NI}$ \\
\hline Ethanol production & $\mathrm{NI}$ & $\mathrm{NI}$ & $\mathrm{NI}$ \\
\hline Fish and shellfish processing & $\mathrm{Nl}$ & 1570 & $\mathrm{NI}$ \\
\hline Fruit and vegetables & $3-65.3$ & 84 & $301-1132$ \\
\hline Grain milling & $\mathrm{NI}$ & $\mathrm{NI}$ & $\mathrm{NI}$ \\
\hline Meat processing & $0.02-51.2$ & $135-1440$ & 481.25 \\
\hline Oilseed processing and vegetable oil refining & $0.02-166$ & $0.15-153$ & $\mathrm{NI}$ \\
\hline Olive oil processing and refining & $\mathrm{NI}$ & $130-300$ & $\mathrm{NI}$ \\
\hline Soft drinks and nectar/juice & $0.05-34.4$ & 29 & 88 \\
\hline Starch production & $5-42.8$ & 29 & $130-5107$ \\
\hline Sugar manufacturing & $0.04-128$ & 980 & 4021 \\
\hline All FDM subsectors & $0.02-166$ & $0.15-1440$ & $88-5107$ \\
\hline
\end{tabular}

$\mathrm{N} /$ no information provided

Table 4 Ranges of yearly average concentrations of COD in the effluent of the WWTP [12]

\begin{tabular}{|c|c|c|c|}
\hline \multirow[t]{2}{*}{ FDM subsector } & \multicolumn{3}{|c|}{ Yearly average COD concentration (mg/l) } \\
\hline & Direct discharge & Indirect discharge & Landspreading \\
\hline Animal feed & 19-155 & $778-8890$ & $\mathrm{NI}$ \\
\hline Brewing & $16-85$ & $111-5779$ & $\mathrm{NI}$ \\
\hline Dairies & $8-147$ & $40-4475$ & $20.1-1001$ \\
\hline Ethanol production & $41-65$ & $\mathrm{Nl}$ & $\mathrm{NI}$ \\
\hline Fish and shellfish processing & $\mathrm{NI}$ & 5741 & $\mathrm{NI}$ \\
\hline Fruit and vegetables & $13-187$ & 2319 & $2205-5402$ \\
\hline Grain milling & $\mathrm{NI}$ & $\mathrm{Nl}$ & $\mathrm{NI}$ \\
\hline Meat processing & $22-259$ & $406-3800$ & 1692 \\
\hline Oilseed processing and vegetable oil refining & $15-363$ & $53-5561$ & $\mathrm{Nl}$ \\
\hline Olive oil processing and refining & $\mathrm{Nl}$ & $53-645$ & $\mathrm{NI}$ \\
\hline Soft drinks and nectar/juice & $6-78$ & $1537-3253$ & 3322 \\
\hline Starch production & $31-284$ & 76.25 & $513-11,333$ \\
\hline Sugar manufacturing & $22-132$ & 4675 & 5556 \\
\hline All FDM subsectors & $6-363$ & $40-8890$ & $20.1-11,333$ \\
\hline
\end{tabular}

$\mathrm{N} /$ no information provided

present a summary of data regarding TSS, COD, TN and TP emissions to water across the FDM subsectors.

Data in Tables 3, 4, 5 and 6 show that concentration levels of indirect discharges are higher than for those related to direct discharges. This is logical, since indirect discharges will be further treated by a downstream WWTP. There are significant differences of concentration levels in terms of pollutants and FDM subsectors, which can be explained by the different types of raw materials used and processes carried out.
Table 7 presents a summary of the data received in relation to channelled dust emissions to air across some FDM subsectors.

\section{Discussion}

The data collection and the discussions within the TWG revealed a number of issues that may need to be addressed during the next (second) review of the FDM BREF. These issues include the following: 
Table 5 Ranges of yearly average concentrations of TN in the effluent of the WWTP [12]

\begin{tabular}{llll}
\hline FDM subsector & \multicolumn{2}{l}{ Yearly average TN concentration $(\mathbf{m g} / \mathbf{l})$} & Landspreading \\
\cline { 2 - 4 } & Direct discharge & Indirect discharge & $\mathrm{NI}$ \\
\hline Animal feed & $2.4-12$ & $89-231$ & $\mathrm{NI}$ \\
Brewing & $4.8-25$ & $26.5-81.5$ & $4.2-111$ \\
Dairies & $1.1-23.4$ & $38-214$ & $\mathrm{NI}$ \\
Ethanol production & $\mathrm{NI}$ & $\mathrm{NI}$ & $\mathrm{NI}$ \\
Fish and shellfish processing & $\mathrm{NI}$ & $\mathrm{NI}$ & $9-105$ \\
Fruit and vegetables & $0.4-22.8$ & 10.2 & $\mathrm{NI}$ \\
Grain milling & $\mathrm{NI}$ & $\mathrm{NI}$ & 53 \\
Meat processing & $2.4-17.9$ & $33-358$ & $\mathrm{NI}$ \\
Oilseed processing and vegetable oil refining & $0.9-15.3$ & $2.5-110$ & $\mathrm{NI}$ \\
Olive oil processing and refining & $\mathrm{NI}$ & 4 & 11.7 \\
Soft drinks and nectar/juice & $1.3-4.1$ & 10 & $55-2150$ \\
Starch production & $3-13.4$ & 4.3 & 86 \\
Sugar manufacturing & $1.7-26.3$ & 265 & $4.2-2150$ \\
All FDM subsectors & $0.4-26.3$ & $4-358$ & \\
\hline
\end{tabular}

$\mathrm{Nl}$ no information provided

Table 6 Ranges of yearly average concentrations of TP in the effluent of the WWTP [12]

\begin{tabular}{|c|c|c|c|}
\hline \multirow[t]{2}{*}{ FDM subsector } & \multicolumn{3}{|c|}{ Yearly average TP concentration (mg/l) } \\
\hline & Direct discharge & Indirect discharge & Landspreading \\
\hline Animal feed & $0.2-2.8$ & $1-118$ & $\mathrm{NI}$ \\
\hline Brewing & $0.5-4.3$ & $1.4-89$ & $\mathrm{Nl}$ \\
\hline Dairies & $0.1-6.3$ & $3.2-75$ & $0.14-1.3$ \\
\hline Ethanol production & $0.8-1.1$ & $\mathrm{NI}$ & $\mathrm{NI}$ \\
\hline Fish and shellfish processing & $\mathrm{NI}$ & $\mathrm{NI}$ & $\mathrm{Nl}$ \\
\hline Fruit and vegetables & $0.2-16$ & $2.2-22.3$ & $2-23$ \\
\hline Grain milling & $\mathrm{Nl}$ & $\mathrm{NI}$ & $\mathrm{NI}$ \\
\hline Meat processing & $0.4-6.2$ & $3.9-47.1$ & $5.1-9.4$ \\
\hline Oilseed processing and vegetable oil refining & $0.1-39$ & $0.7-2655$ & $\mathrm{Nl}$ \\
\hline Olive oil processing and refining & $\mathrm{NI}$ & $6-12$ & $\mathrm{Nl}$ \\
\hline Soft drinks and nectar/juice & $0.1-2.4$ & $18-30$ & $2.1-3.3$ \\
\hline Starch production & $0.2-4.8$ & $0.8-2.4$ & $4.4-380$ \\
\hline Sugar manufacturing & $0.1-2.7$ & $1.4-2$ & $10-14$ \\
\hline All FDM subsectors & $0.1-39$ & $0.7-2655$ & $0.1-380$ \\
\hline
\end{tabular}

$\mathrm{N} / \mathrm{no}$ information provided

- The first review of the FDM BREF collected data related to emissions to water (TSS, COD, TOC, TN and TP) expressed in specific loads. However, it was not possible to derive BAT-AELs expressed as specific loads due to: (1) the fact that BAT-AELs expressed as concentrations and BAT-AEPLs for waste water discharge were sufficient from an environmental point of view; (2) the confidentiality of the data necessary to calculate the specific loads, as the yearly production and the waste water flow were considered confidential by the TWG; (3) the difficul- ties to associate the specific loads with the performance of process-integrated techniques; (4) the lack of data for some FDM sectors and/or products.

- Collection of information on on-site combustion plants with a rated thermal input of less than 50 MWh and which generate hot gases that are not used for direct contact heating, drying or any other treatment of objects or materials should be considered during the next review of the FDM BREF, while taking into account the information exchange foreseen under Directive (EU) 2015/2193. 
Table 7 Ranges of channelled dust emissions to air (adapted from [12])

\begin{tabular}{llc}
\hline FDM subsector & Emission source & $\begin{array}{c}\text { Average dust concentration } \\
\text { over the sampling period (mg/ } \\
\mathbf{N m}^{\mathbf{3}} \text { ) }\end{array}$ \\
\hline Animal feed & Drying of green fodder & $116.2-184.2$ \\
& Compound feed manufacturing & $0.01-59.7$ \\
Brewing & Handling and processing of malt and adjuncts & $0.02-138.1$ \\
Dairies & Drying processes & $0.1-198.0$ \\
Grain milling & Grain cleaning and milling & $0.1-84.0$ \\
Oilseed processing and vegetable oil & Handling and preparation of seeds, drying and cooling of meal & $0.01-48.1$ \\
$\quad$ refining & & $0.16-78.72$ \\
Starch production & Drying of starch, protein and fibre & $1.1-1955.9^{\text {a }}$ \\
\hline
\end{tabular}

${ }^{a}$ Concentration normalised at $16 \% \mathrm{O}_{2}$

- Clarify the boundaries of the installation as far as energy consumption is concerned (e.g. for sugar manufacturing, brewing or for oilseed processing and vegetable oil refining).

- Collect information on conversion factors between different forms of energy.

- Collect information on $\mathrm{PM}_{25} / \mathrm{PM}_{10}$ emissions from FDM subsectors.

- Collect information on emissions from oilseed processing and vegetable oil refining installations performing soap-stock splitting.

- Collect information on the impact of the abatement of $\mathrm{SO}_{\mathrm{X}}$ emissions to air on the waste water generation.

- Collect information on dust emissions from pet food manufacturing.

- Collect information on emissions from fish smoke kilns.

- Collect information on emissions of total volatile organic carbon and other compounds (e.g. PAHs) from meat smoke kilns as well as on the use of purified smoke.

- Collect information on techniques to reduce channelled total volatile organic carbon emissions from oilseed processing and vegetable oil refining.

- Collect information on the influence of the physical state of the starch on the energy consumption in starch production.

- Collect information on the effect of hot gas recirculation on the $\mathrm{SO}_{\mathrm{X}}$ emission levels from high-temperature beet pulp drying.

\section{Conclusions}

A thorough exchange of information took place over 5 years in the context of the review of the FDM BREF undertaken pursuant to Directive 2010/75/EU, involving technical experts representing a variety of stakeholders (EU Member States, industrial organisations, non-governmental organisations for the protection of the environment and the European Commission).

KEIs were defined for emissions to air and water, and for energy and water consumption. Afterwards, a data collection process for a variety of FDM installations across Europe was designed and carried out. Real plant-specific data were collected for the first time under the IED framework for the FDM sector, giving a reliable depiction of the key environmental issues, mainly for emissions to water, emissions to air, and energy and water consumption. Information on the techniques used by industry to tackle those emissions and to reduce that consumption was also collected. The analysis of the data provided the basis for the derivation of the BAT conclusions for the food, drink and milk industries. The BAT derivation was a collective, participative, iterative and evidence-based exercise of the TWG set up for that purpose.

The development of these EU environmental standards for the FDM sector will be the reference for the operation of around 2800 installations in Europe until the FDM BREF is reviewed again. This paper highlights the main normative, organisational and procedural factors addressed during the environmental policy integration carried out to develop this case of policy implementation. The IED creates a level playing field for industry, aligning environmental performance requirements for industrial installations, and will likely foster enhanced resource efficiency in the FDM industries.

\footnotetext{
Abbreviations

BAT: Best available technique(s), as defined in Article 3(10) of the IED; BATAEL: Best available techniques-associated emission level, as defined in Article 3(13) of the IED; BAT-AEPL: Best available techniques-associated performance emission level, as described in Section 3.3.2 of Commission
} 
Implementing Decision 2012/119/EU; BREF: Best available techniques (BAT) reference document; COD: Chemical oxygen demand; EIPPCB: European Integrated Pollution Prevention and Control Bureau; EU: European Union; FDM BREF: BAT reference document for the food, drink and milk industries; IED: Industrial emissions directive; KEl: Key environmental issue; KoM: Kick-off meeting; TN: Total nitrogen; TP: Total phosphorus; TSS: Total suspended solids; TWG: Technical working group.

\section{Acknowledgements}

The authors would like to express their thanks to Serge Roudier and Anna Atkinson (Joint Research Centre) for their review of this manuscript and helpful comments.

The views expressed are purely those of the author and may not in any circumstances be regarded as stating an official position of the European Commission.

\section{Authors' contributions}

GGS and PK conceptualised and wrote the manuscript. All authors read and approved the final manuscript.

\section{Funding}

All funds for the design and writing of the manuscript have been provided by the Joint Research Centre.

\section{Availability of data and materials}

All data analysed during this study are included in: Giner Santonja, G., Karlis, P., Stubdrup, K.R., Brinkmann, T., Roudier, S., 2019a. Best Available Techniques (BAT) Reference Document for the Food, Drink and Milk Industries. Joint Research Centre. European Commission. https://doi.org/10.2760/243911.

\section{Ethics approval and consent to participate}

Not applicable.

\section{Consent for publication}

Not applicable.

\section{Competing interests}

The authors declare that they have no competing interests.

Received: 1 July 2020 Accepted: 3 November 2020

Published online: 23 November 2020

\section{References}

1. Brinkmann T, Both R, Scalet BM, Roudier S, Delgado Sancho L (2018) JRC reference report on monitoring of emissions to air and water from IED installations. https://doi.org/10.2760/344197

2. Council EU (1996) Council Directive 96/61/EC of 24 September 1996 concerning integrated pollution prevention and control. Off J Eur Union L 257:26-40

3. E-PRTR (2020) The European Pollutant Release and Transfer Register. https ://prtr.eea.europa.eu. Accessed 12 Aug 2020

4. European Commission (2006) Best available techniques (BAT) reference document for the food, drink and milk industries (FDM BREF). European Commission, JRC IPTS EIPPCB

5. European Commission (2012) Commission Implementing Decision 2012/119/EU laying down rules concerning guidance on the collection of data and on the drawing up of BAT reference documents and on their quality assurance referred to in Directive 2010/75/EU of the European Parliament and of the Council on industrial emissions. Off J Eur Union L 63:1-39

6. European Commission (2015) Discussion paper presented at the 8th Forum meeting in 19 October 2015. https://circabc.europa.eu/sd/a/22f91
9af-daee-4fc2-b84f-dc66ba2ba952/5.1\%20Key\%20environmental\%20iss ues.pdf. Accessed 17 March 2020

7. European Commission (2016) Assessment and summary of the member states' implementation reports for the IED. IPPC Directive, SED and WID

8. European Commission (2017) Report from the Commission to the Council and European Parliament on the implementation of Directive 2010/75/EU and final reports on its predecessor legislation. COM/2017/0727 final

9. European Commission (2019) Commission Implementing Decision (EU) 2019/2031 establishing best available techniques (BAT) conclusions for the food, drink and milk industries, under Directive 2010/75/EU of the European Parliament and of the Council. Off J Eur Union L 313:60-93

10. European Parliament and Council (2010) Directive 2010/75/EU of the European Parliament and of the Council of 24 November 2010, on industrial emissions (integrated pollution prevention and control) (recast). Off J Eur Union L 334:17-119

11. European Parliament and Council (2015) Directive (EU) 2015/2193 of the European Parliament and of the Council of 25 November 2015 on the limitation of emissions of certain pollutants into the air from medium combustion plants. Off J Eur Union L 313:1-19

12. Giner Santonja G, Karlis P, Stubdrup KR, Brinkmann T, Roudier S (2019) Best available techniques (BAT) reference document for the food, drink and milk industries. Joint Research Centre, European Commission. https ://doi.org/10.2760/243911

13. Giner Santonja G, Vázquez-Calvo V, Rodríguez-Lepe G (2019) Application of AHP and corrective factors for the determination of best available techniques and emission limit values at installation level: A case study in four cement installations. Sci Total Environ 660:834-840. https://doi. org/10.1016/j.scitotenv.2018.12.473

14. Goulden S, Negev M, Reicher S, Berman T (2019) Implications of standards in setting environmental policy. Environ Sci Policy 98:39-46. https:// doi.org/10.1016/j.envsci.2019.05.002

15. ICF (2018) Indicators for Industrial Emissions Policy, Report 30301614 for DG Environment, ICF. https://circabc.europa.eu/webdav/CircaBC/env/ ied/Library/studies/

16. Lecomte T, Ferrería de la Fuente JF, Neuwahl F, Canova M, Pinasseau A, Jankov I, Brinkmann T, Roudier S, Delgado Sancho L (2017) Best available techniques (BAT) reference document for large combustion plants. European Commission, Joint Research Centre. https://doi.org/10.2760/949

17. Lenschow A, Zito A (1998) Blurring or shifting of policy frames? Institutionalization of the economic-environmental policy linkage in the European Community. Governance 11(4):415-442

18. Nilsson M, Persson $\AA$ (2017) Policy note: Lessons from environmental policy integration for the implementation of the 2030 Agenda. Environ Sci Policy 78:36-39. https://doi.org/10.1016/j.envsci.2017.09.003

19. Persson $\AA$ (2004) Environmental policy integration: an introduction. Stockholm Environment Institute, Stockholm

20. Persson $\AA$ (2007) Different perspectives on EPI. In: Nilsson M, Eckerberg K (eds) Environmental policy integration in practice: shaping institutions for learning. Earthscan, London, pp 25-48

21. Persson $\AA$, Runhaar H (2018) Conclusion: drawing lessons for environmental policy integration and prospects for future research. Environ Sci Policy 85:141-145. https://doi.org/10.1016/j.envsci.2018.04.008

22. Runhaar H, Wilk B, Persson Å, Uittenbroek C, Wamsler C (2018) Mainstreaming climate adaptation: taking stock about "what works" from empirical research worldwide. Region Environ Change 18(4):1201-1210

23. Stead D, Meijers E (2009) Spatial planning and policy integration: concepts, facilitators and inhibitors. Plan Theory Pract 10(3):317-332. https:// doi.org/10.1080/14649350903229752

\section{Publisher's Note}

Springer Nature remains neutral with regard to jurisdictional claims in published maps and institutional affiliations. 